\title{
Evaluating the Effect of Water-Repellent Finishing on Thermal Insulation Properties of Rowing Shirts Using a Thermal Manikin
}

\author{
Derya Tama ${ }^{1,2}$, André Catarino ${ }^{1}$ and Maria José Abreu ${ }^{1}$ \\ ${ }^{1}$ University of Minho, 2C2T-Center for Textile Science and Technology, Campus de Azurem, Guimarães, Portugal \\ ${ }^{2}$ EgeUniversity, Faculty of Engineering, Department of Textile Engineering, 35100 Bornova, Izmir, Turkey
}

Corresponding Author: Derya Tama, derya.tama@ege.edu.tr

\begin{abstract}
The activity of rowing is majorly performed outside, namely on rivers or lakes, and the probability of getting the t-shirt wet due to splash or rain is high. In order to evaluate the impact of water repellent finishing on the thermal insulation, several rowing shirts made with different structures and raw material were tested and compared by means of a thermal manikin, before and after finishing. The shirts were treated with a $5 \%$ of a fluorocarbon-based product water repellent finishing. The heat loss values of rowing shirts were measured by using a thermal manikin and the effective clothing insulation values were calculated. Moreover, the effect of garment design on thermal insulation was investigated by comparing shirts with more than one knitted structure with single knitting structures shirts. Considering the results for the heat loss values, after WRF, the heat flux of rowing shirts was lower. Shirt B and shirt B-1 had higher effective thermal insulation value after WRF, where the other shirts had lower thermal insulation values. Moreover, not only the water repellent finishing, but also the structure of garment is also important in terms of heat loss and thermal insulation.
\end{abstract}

\section{ARTICLE HISTORY}

Received: 04.10.2018

Accepted: 30.10.2019

\section{KEYWORDS}

rowing shirts, thermal comfort, thermal manikin, heat loss, total thermal insulation, effective clothing insulation

\section{ABBREVIATIONS}

$\mathrm{I}_{\mathrm{T}}$

Icle The effective thermal clothing insulation

$\mathrm{I}_{\mathrm{a}} \quad$ Thermal insulation of the boundary air layer

$f_{i} \quad$ Relationship between the surface area of the segment $i$ of the manikin $\left(\mathrm{A}_{\mathrm{i}}\right)$

A The total surface area of the manikin

to The operative temperature $\left[{ }^{\circ} \mathrm{C}\right]$

$\mathrm{t}_{\mathrm{si}} \quad$ Skin surface temperature of the body segment of the manikin

$\overline{\mathrm{Q}}_{\mathrm{si}} \quad$ Sensible heat flux of the manikin obtained by area

CST Constant skin temperature

WRF Water Repellent Finishing

\section{INTRODUCTION}

Nowadays, clothing comfort is one of the most important aspects for consumers, designers and manufacturers. Slater (1985) defined comfort as "a pleasant state of physiological, psychological, neurophysiological and physical harmony between a human being and the environment" [1-3].

Moreover, the term comfort is defined as either "the absence of unpleasantness or discomfort;' or "a neutral state compared to the more active state of pleasure." Therefore, the clothing comfort is classified into four basic groups: psychological, sensory, ergonomic and thermophysiological comfort. Psychological comfort is mainly related to the fashion, colors and design features and acceptability in society which help people to feel confident. The sensory comfort is related with the sensations when a

To cite this article: Tama D, Catarino A, Abreu MJ. 2019. Evaluating the effect of water-repellent finishing on thermal insulation properties of rowing shirts using a thermal manikin, Tekstil ve Konfeksiyon, 29 (4), 279-288. 
fabric comes into contact with the skin e.g. cold, warm, soft or stiff. The ergonomic comfort is related with the shapes, forms and ease of body movement of the wearer. The thermo-physiological comfort, which is the most researched element for improving comfort in clothing, is about the transmission of heat and moisture through fabric [4].

Different variables contribute for thermal comfort perception of a human being, such as air temperature and movement (speed, humidity, activity level, the environment mean radiant temperature), among others, resulting in a complex interaction between man and the environment. Thermal comfort relates body heat production and loss, and thermal manikins are a suitable mean for evaluating the thermal interface of the human body and the surrounding environment [5].

The thermal insulation of clothing has great significance in the thermoregulation process, which keeps body temperature within safe internal temperature boundaries. Clothing thermal insulation depend on factors such as specific design, dimensions and fabric characteristics, namely the air gap between skin and clothing [6]. The former is usually quantified by means of thermal manikins due to their experimental simplicity and repeatability procedures, and precision [7]. The thermal manikins now exist for more than 60 years [8] and provide a good estimate of the total dry heat loss from the body and the distribution of heat flow over the body surface. When in a standard environment, these measures can be used to describe the thermal characteristics of clothing [9].

Rowing is a competitive sport initiated in 1716 on the River Thames and depends on the speed of the shell [10]. Rowing is a highly repetitive action [11] and a periodic movement involving several phases such as catch, drive, finish and recovery [12]. In Northern Europe and Scandinavia, rowing is also a leisure sport practiced in riggers where oarlocks are on the side of the boat [13]. Since nowadays, many clubs developed an interest in the leisure-rowing scene and clothing for the rowing sport has become a subject for research and development.

In long distance rowing tours, one of the cardiac output has to be directed to the skin for heat exchange. The temperature regulation affects the performance of athletes and also may limit the maximum performance in hot climates. When the core temperature reaches $40^{\circ} \mathrm{C}$, cellular damage occurs rapidly, initiating a cascade of events that may lead to organ failure and possible fatality [14]. After the exercise, the high amount of heat produced during rowing needs to be unloaded. This puts an additional burden to the already stressed central nervous system and can lead in some case to collapse, loss of consciousness and, if untreated, to fatality [13].

Rowing is an outdoor sport, being water the place where it is practiced, namely lakes and rivers. To protect the athletes, features like water-repellent and windproof are of paramount importance in rowing shirts. However, an exaggerated insulation and low absorbency may lead to a significant increase of skin temperature, leading to higher moisture accumulation between skin and clothing. In order to overcome this, sports clothing should comply with some requisites: they need to be breathable, well fit, maintain the athlete in fresh condition by allowing an adequate heat change between the body and the environment [15]. As a result, sportswear should be able to protect the wearer from external elements such as wind, sun, rain and snow, but also be capable of maintaining the heat balance between excess heat produced by the wearer due to increased metabolic rate. Subsequently, the wear comfort of sportswear is an important property for a sportsperson. If, for example, an active person wears a clothing system with poor breathability, heart rate and body temperatures will increase more rapidly compared to wearing breathable sportswear $[5]$.

Therefore, in order to prevent the high heat loss in thermoregulation using a high amount of energy due to the splashed water and the wind [16], a water-repellent finish can be applied to the rowing shirts. Moreover, water repellent finishing is an important factor to prevent health issues due to contaminated water. Awareness of environmental protection has increased during last decades and regarding to rowing sport, protecting the rower from all environmental impacts, namely contaminated water, which can result in skin problems [9], became one of the goals of manufacturers. Also, due to the possible exposure to splash water and rain, the body of the rower can easily get wet. When the shirt of the rower is getting wet, his body cools down. To avoid this, the shirt could be prepared with a water-repellent finish. If a water-repellent finish is applied, it is crucial that it will not deteriorate the breathability [5].

There are several repellents, which are currently used in water repellent finishing such as paraffin, stearic acidmelamine, silicone and fluorocarbons. The paraffin repellents, which are one of the earliest water repellents, increase the adhesion of the finish to polar fibre surfaces by forming polar-non-polar junctions. The paraffin repellents are available at relatively low costs and they generate uniform waterproof effects. However, there are also disadvantages including an increase of flammability and the lack of durability to laundering and dry cleaning. Furthermore, they have low air and vapour permeability, which limits the use of paraffin-based repellents [18].

The other class of water-repellent materials are the compounds formed by reacting stearic acid and formaldehyde with melamine constitute. There are some disadvantages of stearic acid-melamine repellents such as a tendency to exhibit finish mark-off, decreased fabric tear strength and abrasion resistance, changes in shade of dyed fabric, and release of formaldehyde [18]. Due to the high water, oil and soil repellence of finished fabrics [19], fluorocarbons are the most used water repellent finishes. Moreover, fluorocarbon is appropriate to apply on fabrics based on synthetic fibres and their mixtures with cellulosic fibre [17]. 
The main purpose of this study was to analyse the influence of water repellent finishing on thermal insulation properties of rowing shirts, which were manufactured in different materials and knitting structures. Some previous researches $[5,9,20]$ were presented before such as the initial studies of this type of product, as parts of the conducted project. The optimal combination of base fabric constructions were discussed [20] as the part of the same project.

\section{MATERIAL AND METHOD}

\subsection{Rowing shirts}

The Shirt B and Shirt D produced by the collaborating company for outdoor rowing were tested in the present research. Since the former shirts had three combined knitting structures each, shirts with single structures were manufactured and named as Shirt B-1, B-2 and B-3 of Shirt B and as Shirt D-1, D-2 and D-3 of Shirt D in order to also observe the influence of garment design on thermal insulation. In addition, a $100 \%$ Cotton shirt, which is a well-known product and usually used during rowing practice, was involved in the study to compare its behaviour with the tested rowing shirts. The compositions, knitted structures and the shirt codes are given in Table 1. All the shirts were produced in the same conditions, using seamless knitting machines.

Table 1. The compositions, knitting structures and the codes of shirts

\begin{tabular}{|c|c|c|c|c|c|}
\hline Code & Composition & Knitting Structure & The Stitch Diagram* & $\begin{array}{c}\text { Fabric } \\
\text { Thickness }\end{array}$ & $\begin{array}{c}\text { Machine } \\
\text { Gauge }\end{array}$ \\
\hline Shirt A & $100 \%$ Cotton & Single jersey & & 1,096 & E24 \\
\hline Shirt B & \multirow{4}{*}{$\begin{array}{l}\text { 60\% Polyamide } \\
\text { (black) } \\
\text { 35\% Polyester } \\
\text { (grey) } \\
\text { 5\% Elastane } \\
\text { (transparent) }\end{array}$} & $\begin{array}{c}\text { Composition of structures in } \\
\text { different areas used in shirt B-1, B-2 } \\
\text { and B-3 }\end{array}$ & & & E26 \\
\hline Shirt B-1 & & False Rib 1 & & 1,317 & E26 \\
\hline Shirt B-2 & & False Rib 2 & & 1,606 & E26 \\
\hline Shirt B-3 & & Single Jersey Jacquard 1 & & 1,1 & E26 \\
\hline Shirt D & \multirow{4}{*}{$\begin{array}{c}\text { 60\% Polyamide } \\
\text { (black) } \\
\text { 35\% Polypropylene } \\
\text { (grey) } \\
\text { 5\% Elastane } \\
\text { (transparent) }\end{array}$} & $\begin{array}{l}\text { Composition of structures in } \\
\text { different areas used in shirt D-1, D- } \\
2 \text { and D-3 }\end{array}$ & - & & E26 \\
\hline Shirt D-1 & & Single Jersey Jacquard 2 & & 0,956 & E26 \\
\hline Shirt D-2 & & Single Jersey Jacquard 3 & 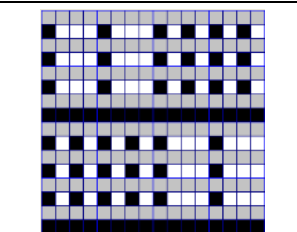 & 0,993 & E26 \\
\hline Shirt D-3 & & False Rib 3 & & 1,248 & E26 \\
\hline
\end{tabular}

*Colour codes: Knit loops: Light grey and black; White: float loop; Light grey: polyester yarn or polypropylene yarn; black: polyamide yarn.

The $100 \%$ cotton long sleeve basic shirt, which was coded as A, can be seen in Figure 1. The shirt was designed with conventionally sewed side seams and round-necked. 


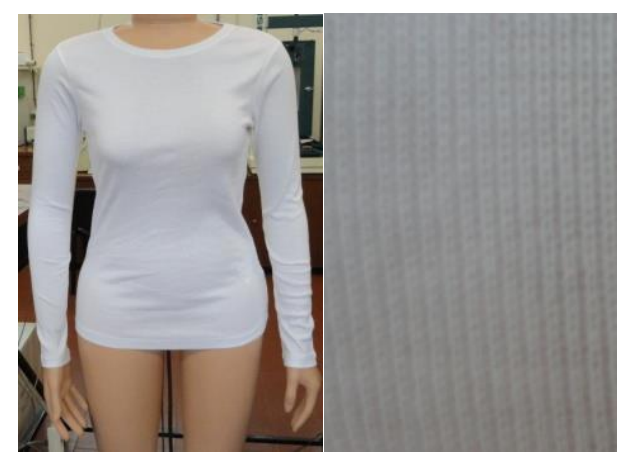

Figure 1. 100\% cotton long sleeve basic shirt

The shirt B, which was a turtleneck raglan sleeve tightfitting shirt, was a combination of shirts B-1, B-2 and B-3, located on particular regions of the garment (Figure 2). Structure B-1 was mostly located on upper and lower arms, as well as on the pelvis while structure B-2 was used on the shoulders, collar and the centre of the chest covering the body parts, where the lungs are located. Furthermore, structure B-3 was positioned as a vertical stripe of about 5 $\mathrm{cm}$ on the back as well as near the armpits and on both sides of the shirt.

Shirt D was a rounded-neck raglan sleeve tight-fitting shirt produced by combining shirts D-1, D-2 and D-3 (Figure 3). Structure D-1 covered the most parts of the chest as well as blade bones, lower back, upper and lower arms. Structure D-2 was located on the centre chest, armpits and as two stripes one above and the other one below of each sleeve. Structure D-3 was used on the back of the shirt and located at the shoulders and the top sides of the upper arms as well as at both sides of the pelvis.

\subsection{Water-Repellent Finishing}

All shirts were treated with $5 \%$ of a fluorocarbon-based product: Imofob FMU. The finishing was selected and applied by the collaborating company regarding to the market expectations and their knowledge. Moreover, not only the water-repellent finishing but also the fabric constructions and garment design were evaluated in this study. Therefore, the treatment was done by the chemicals that collaborating company recommended.

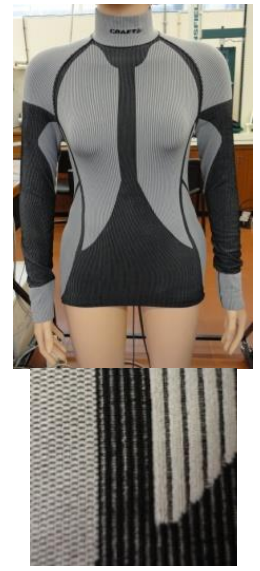

B

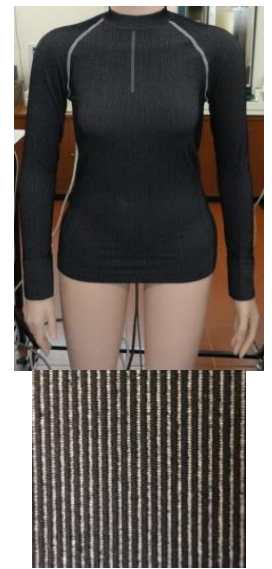

B-1

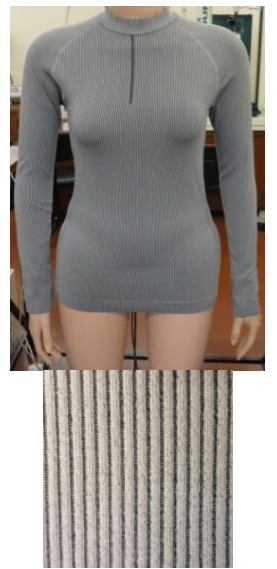

B-2

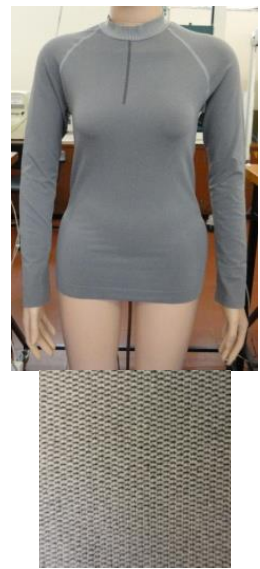

B-3

Figure 2. The type B shirts and views of the knitted structures

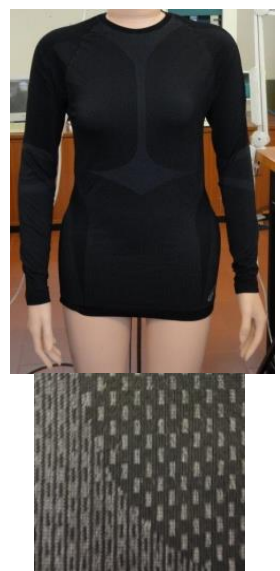

$\mathrm{D}$

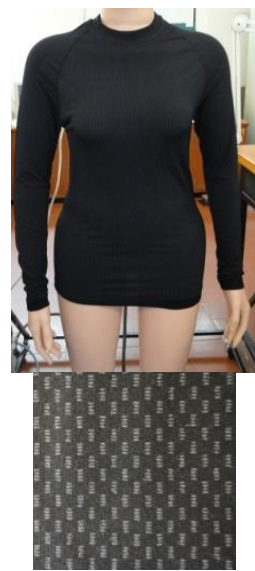

D-1

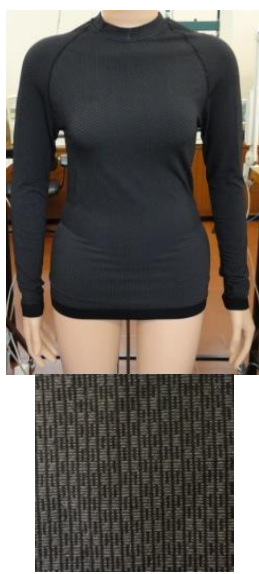

D-2

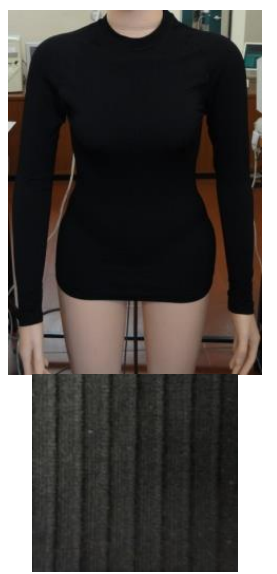

D-3

Figure 3. The type D shirts and views of the knitted structures 
The characteristics of Imofob FMU are favourable for the usage on sports shirts, namely on rowing, because Fluorocarbon provides fibre surfaces with the lowest surface energies compared to other repellent finishes in use. It's a product for water-repellent articles based on synthetic fibres and their mixtures with cellulosic fibres [17].

The special properties of this product are good water and oil repellent characteristics, soft touch (even on printed items with pigments) and fastness in washing and dry cleaning. Furthermore, the product is suitable for applications with spray or in drum machines (on the fabricated article) [5].

\subsection{Test Equipment}

In order to observe heat loss, a female model thermal manikin (PT-Teknik, Denmark) (Figure 4), which has similar size and configurations with an adult woman, was used in this study. The thermal manikin is installed in the research laboratory of the (2C2T- Centre for Textile Science and Technology) of the University of Minho in Portugal. It only senses dry heat transfer and is divided in 20 thermally independent sections. The tests were conducted by placing the thermal manikin inside a climatic chamber which is able to achieve temperatures around 15 ${ }^{\circ} \mathrm{C}$ to $35{ }^{\circ} \mathrm{C}$ and relative humidity around $35 \%$ to $85 \%$. Throughout the period of analysis, the thermal manikin was placed around $0.1 \mathrm{~m}$ above the floor with hanging arms and legs.

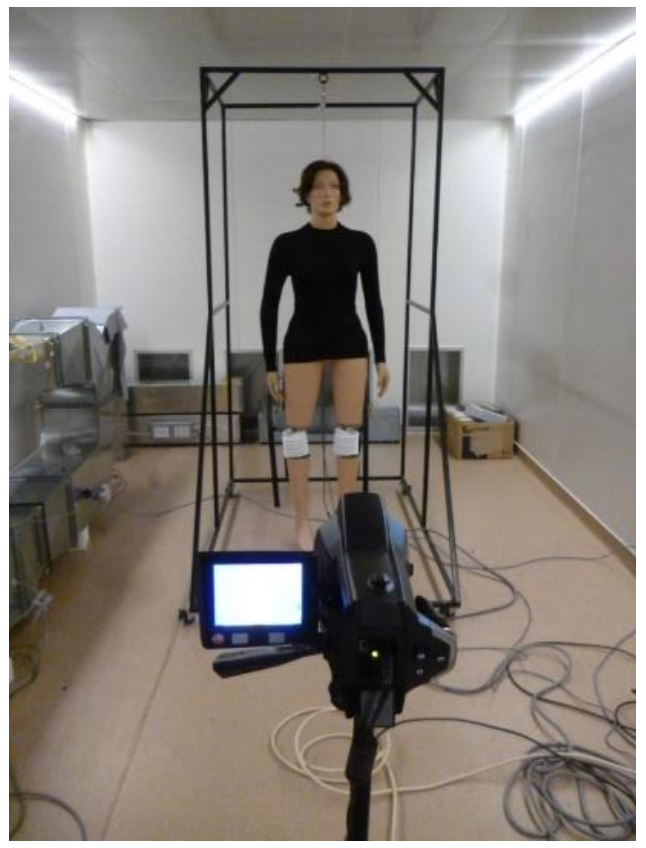

Figure 4.Thermal manikin

\subsection{Experimental Procedure}

The tests were carried out according to "ISO 9920:2007: Ergonomics of the thermal environment - Estimation of thermal insulation and water vapour resistance of a clothing ensemble" standard [21]. The trials were performed with constant skin temperature mode and the skin temperature of thermal manikin was set to $33 \pm 0,2^{\circ} \mathrm{C}$ regarding to ISO 9920. The thermal manikin was dressed with the rowing shirts and for the measurement of heat loss, the manikin was kept in a stationary standing position, with its legs hanging straight and the arms hanging straight at its sides. The tests were performed at constant ambient temperature of $23 \pm 1,5^{\circ} \mathrm{C}$ and relative humidity of $60 \pm 5 \%$. The test time of each measurement was 60 minutes. The mean skin temperature, the heat flux of the manikin, and the room physical parameters were continuously monitored on computers. At the end of each measurement, the heat loss was obtained and recorded to the computer. Afterwards, the total thermal clothing insulation $\left(\mathrm{I}_{\mathrm{T}}\right)$ and the effective thermal clothing insulation $\mathrm{I}_{\text {cle }}$ were calculated according to the obtained data.

In order to calculate $\mathrm{I}_{\mathrm{T}}$ and $\mathrm{I}_{\mathrm{cl}}$, the methods existing in literature were investigated. There are three thermal insulation calculation methods in literature; the serial, the global and the parallel methods. Due to the operation of thermal manikin was set with the constant skin temperature (CST) in this study, the global method was chosen with respect to the research conducted by Oliveira et al. (7) In their research, the thermal insulation of clothing was compared according to the three thermal insulation calculation methods and different manikin regulation modes in the body parts. Oliveira et al. obtained that, when the CST regulation mode is used, the general formula for defining the whole body resistance, i.e., the global method turns into a summation of local resistances according to a typical parallel model [7]. Moreover, in another research, Oliveira at al. found out that the serial and global methods always had statistically significant difference, while the global and parallel methods had not significant difference [22]. In this research, the insulation from skin surface to the environment, $\mathrm{I}_{\mathrm{T}}$, was determined by using the global method under static conditions. In this method, the sum of all heat losses weighted areas and skin temperatures of each body segment is calculated before $\mathrm{I}_{\mathrm{T}}$ is obtained, thus assuming the manikin has having only one segment. The general equation for defining the whole body resistance is:

$$
I_{T}=\frac{\sum_{i}\left(f_{i} \times t_{s i}\right)-t_{0}}{\sum\left(f_{i} \times \dot{Q}_{s i}\right)}
$$

The $I_{c l e}$, consisting of the difference between $I_{T}$ and $I_{a}$ (thermal insulation of the boundary air layer) is calculated by equation 2 , considering $I_{a}$ is measured by operating the manikin nude.

$$
I_{c l e}=I_{T}-I_{a}
$$

Where:

$f_{i}=$ relationship between the surface area of the segment $i$ of the manikin $\left(\mathrm{A}_{\mathrm{i}}\right)$ and the total surface area of the manikin $\mathrm{A}\left(f_{i}=\mathrm{A}_{\mathrm{i}} / \mathrm{A}\right)$.

$t_{0}=$ the operative temperature $\left({ }^{\circ} \mathrm{C}\right)$ 
$f_{i}=\operatorname{re}\left({ }^{\circ} \mathrm{C}\right)$

$\overline{\mathrm{Q}}_{\mathrm{si}}=$ sensible heat flux of the manikin obtained by area.

\subsection{Statistical Analysis}

In this study, statistical analysis was performed by using last version of SPSS statistical analysis package software. Independent-samples t-tests were conducted to compare heat loss and $\mathrm{I}_{\text {cle }}$ values for tests conducted with the specimens before and after WRF. Post hoc least significant difference tests were also carried out by using Bonferroni correction.

\section{RESULTS AND DISCUSSION}

\subsection{Heat loss}

The heat loss values for all rowing shirts were presented and comparisons were done graphically and statistically between the obtained data. Figure 5, 6 and 7 shows the heat loss from nine manikin body segments, which were related with upper garment conducted before and after WRF.

When the heat loss from the skin to the environment is higher, the temperature will decrease and the freshness feeling will be more intense [23, 24]. While the material absorbs and conducts the heat well, the sensation of being a "coolest" garment emerges. Thus, heat loss is closely related to thermal insulation, where they are inversely proportional parameters.

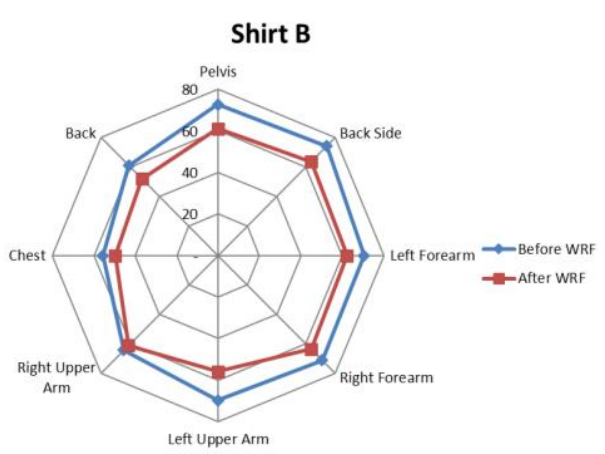

Shirt B-2
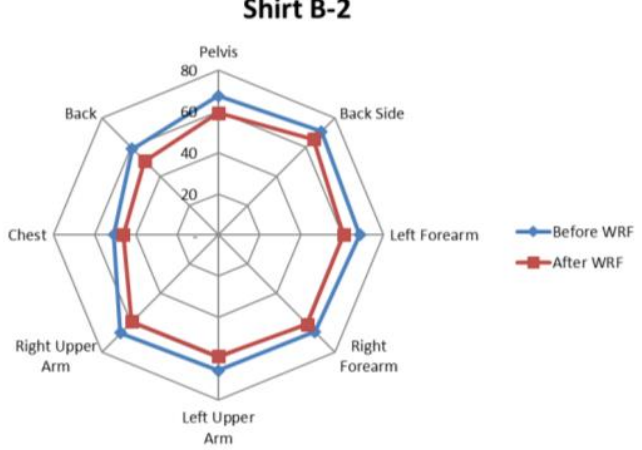

Shirt A

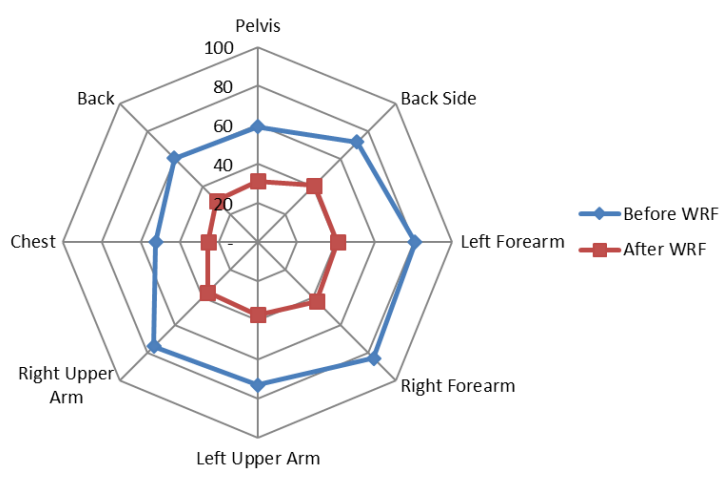

Figure 5. Heat loss values in $\mathrm{W} / \mathrm{m}^{2}$ from the body segments of shirt A

As it can be seen in Figure 5, the heat loss change was around 50\% after water repellent finishing treatment. Shirt A was produced from $100 \%$ cotton fabric. Water repellent finishing treatment changes the features of cotton from hydrophilic to hydrophobic. Therefore, it can be said that, water repellent finishing had considerable influence on thermal insulation properties of rowing shirts that produced from $100 \%$ cotton fabrics, in positive way for outdoor sports if one considers cold environment.

Figure 6. Heat loss values in $\mathrm{W} / \mathrm{m}^{2}$ from the body segments of shirts B, B-1, B-2 and B-3

Figure 6 shows the heat loss values for shirts B, B-1, B-2 and B-3. It can be said that, the heat loss values decreased after water repellent finishing treatment for each shirt. The heat loss changes for shirts B, B-1, B-2 and B-3 were 13\%, 12\%, $10 \%$ and $16 \%$, respectively. 


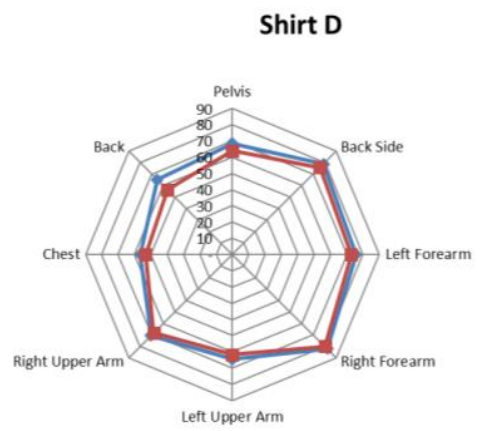

Shirt D-2

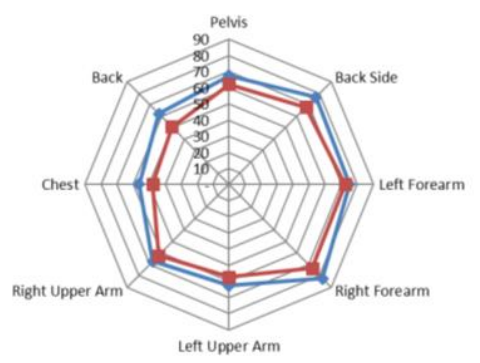

Shirt D-1

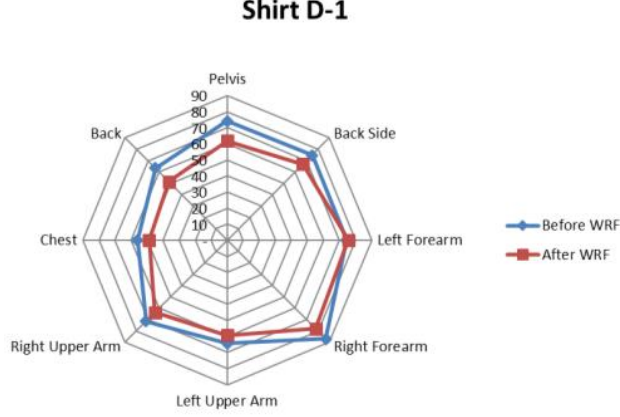

Shirt D-3

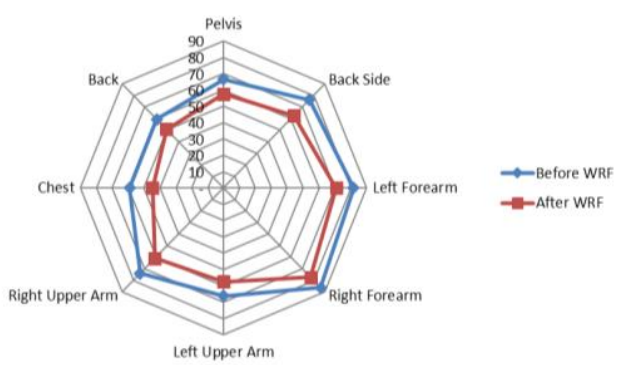

Figure 7. Heat loss values in $\mathrm{W} / \mathrm{m}^{2}$ from the body segments of shirts D, D-1, D-2 and D-3

Figure 7 demonstrates the heat loss values for shirts D, D-1, D-2 and D-3. With respect to the graphs, it can be seen that, for each shirt the heat loss values decreased after water repellent finishing treatment as other specimens. The heat loss changes for shirts D, D-1, D-2 and D-3 were 4\%, $11 \%, 11 \%$ and $16 \%$, respectively.

Table 2. The T-Test results for heat loss values $\left(\mathrm{W} / \mathrm{m}^{2}\right)$

\begin{tabular}{|c|c|c|c|c|c|c|c|}
\hline & & $\mathbf{N}$ & Mean & $\begin{array}{c}\text { Std. } \\
\text { Deviation }\end{array}$ & $\mathbf{t}$ & df & $\mathbf{p}$ \\
\hline \multirow{2}{*}{ Shirt A } & Before WRF & 30.00 & 80.88 & 0.80 & \multirow{2}{*}{258.02} & \multirow{2}{*}{37.50} & \multirow{2}{*}{0.000} \\
\hline & After WRF & 30.00 & 40.52 & 0.31 & & & \\
\hline \multirow{2}{*}{ Shirt B } & Before WRF & 30.00 & 81.32 & 1.37 & \multirow{2}{*}{54.16} & \multirow{2}{*}{31.31} & \multirow{2}{*}{0.000} \\
\hline & After WRF & 30.00 & 67.48 & 0.27 & & & \\
\hline \multirow{2}{*}{ Shirt B-1 } & Before WRF & 30.00 & 78.93 & 0.50 & \multirow{2}{*}{124.63} & \multirow{2}{*}{35.58} & \multirow{2}{*}{0.000} \\
\hline & After WRF & 30.00 & 66.87 & 0.17 & & & \\
\hline \multirow{2}{*}{ Shirt B-2 } & Before WRF & 30.00 & 78.19 & 1.61 & \multirow{2}{*}{42.27} & \multirow{2}{*}{32.35} & \multirow{2}{*}{0.000} \\
\hline & After WRF & 30.00 & 65.39 & 0.39 & & & \\
\hline \multirow{2}{*}{ Shirt B-3 } & Before WRF & 30.00 & 72.77 & 1.14 & \multirow{2}{*}{70.85} & \multirow{2}{*}{35.48} & \multirow{2}{*}{0.000} \\
\hline & After WRF & 30.00 & 57.16 & 0.38 & & & \\
\hline \multirow{2}{*}{ Shirt D } & Before WRF & 30.00 & 86.72 & 1.15 & \multirow{2}{*}{60.22} & \multirow{2}{*}{32.09} & \multirow{2}{*}{0.000} \\
\hline & After WRF & 30.00 & 73.69 & 0.27 & & & \\
\hline \multirow{2}{*}{ Shirt D-1 } & Before WRF & 30.00 & 85.08 & 1.20 & \multirow{2}{*}{50.58} & \multirow{2}{*}{31.84} & \multirow{2}{*}{0.000} \\
\hline & After WRF & 30.00 & 73.69 & 0.27 & & & \\
\hline \multirow{2}{*}{ Shirt D-2 } & Before WRF & 30.00 & 83.99 & 0.79 & \multirow{2}{*}{87.25} & \multirow{2}{*}{35.89} & \multirow{2}{*}{0.000} \\
\hline & After WRF & 30.00 & 70.75 & 0.27 & & & \\
\hline \multirow{2}{*}{ Shirt D-3 } & Before WRF & 30.00 & 83.99 & 0.79 & \multirow{2}{*}{100.89} & \multirow{2}{*}{33.74} & \multirow{2}{*}{0.000} \\
\hline & After WRF & 30.00 & 68.94 & 0.23 & & & \\
\hline
\end{tabular}

Table 2 shows the t-test results of average heat loss values for each shirt. With respect to the obtained data, it was clear that, there was a significant difference in average heat loss scores for all shirts between the tests conducted before and after WRF.

\subsection{Clothing insulation}

The total thermal insulation and effective thermal insulation values were calculated regarding to global method and the minimum, maximum, mean and standard deviation values are given in Table 3. 
Table 3. Total thermal insulation and effective thermal insulation values of all shirts.

\begin{tabular}{|c|c|c|c|c|c|c|c|c|c|}
\hline & & \multicolumn{4}{|c|}{$\mathbf{I}_{\mathrm{T}}\left[\mathbf{m}^{2} \cdot \mathbf{K} \cdot \mathbf{W}^{-1}\right]$} & \multicolumn{4}{|c|}{$\mathbf{I}_{\text {cle }}\left[\mathbf{m}^{2} . \mathbf{K} \cdot \mathbf{W}^{-1}\right]$} \\
\hline & & Min. & Max. & Mean & $\begin{array}{c}\text { Std. } \\
\text { Deviation }\end{array}$ & Min. & Max. & Mean & $\begin{array}{c}\text { Std. } \\
\text { Deviation }\end{array}$ \\
\hline \multirow{2}{*}{ Shirt A } & Before WRF & 0.124 & 0.129 & 0.127 & 0.001 & 0.016 & 0.022 & 0.019 & 0.002 \\
\hline & After WRF & 0.117 & 0.120 & 0.118 & 0.001 & 0.006 & 0.008 & 0.007 & 0.001 \\
\hline \multirow{2}{*}{ Shirt B } & Before WRF & 0.125 & 0.133 & 0.129 & 0.002 & 0.017 & 0.026 & 0.023 & 0.003 \\
\hline & After WRF & 0.138 & 0.140 & 0.139 & 0.001 & 0.027 & 0.029 & 0.028 & 0.000 \\
\hline \multirow{2}{*}{ Shirt B-1 } & Before WRF & 0.125 & 0.128 & 0.127 & 0.001 & 0.018 & 0.025 & 0.021 & 0.002 \\
\hline & After WRF & 0.132 & 0.133 & 0.133 & 0.000 & 0.021 & 0.023 & 0.022 & 0.001 \\
\hline \multirow{2}{*}{ Shirt B-2 } & Before WRF & 0.121 & 0.130 & 0.125 & 0.003 & 0.016 & 0.022 & 0.020 & 0.002 \\
\hline & After WRF & 0.127 & 0.130 & 0.128 & 0.001 & 0.017 & 0.018 & 0.017 & 0.000 \\
\hline \multirow{2}{*}{ Shirt B-3 } & Before WRF & 0.122 & 0.131 & 0.129 & 0.002 & 0.018 & 0.028 & 0.024 & 0.003 \\
\hline & After WRF & 0.131 & 0.135 & 0.133 & 0.001 & 0.021 & 0.023 & 0.022 & 0.000 \\
\hline \multirow{2}{*}{ Shirt D } & Before WRF & 0.131 & 0.139 & 0.136 & 0.002 & 0.024 & 0.032 & 0.029 & 0.002 \\
\hline & After WRF & 0.137 & 0.140 & 0.139 & 0.001 & 0.023 & 0.025 & 0.024 & 0.001 \\
\hline \multirow{2}{*}{ Shirt D-1 } & Before WRF & 0.130 & 0.137 & 0.135 & 0.002 & 0.025 & 0.031 & 0.028 & 0.002 \\
\hline & After WRF & 0.134 & 0.135 & 0.134 & 0.000 & 0.019 & 0.021 & 0.019 & 0.001 \\
\hline \multirow{2}{*}{ Shirt D-2 } & Before WRF & 0.127 & 0.138 & 0.133 & 0.003 & 0.019 & 0.031 & 0.025 & 0.003 \\
\hline & After WRF & 0.128 & 0.129 & 0.129 & 0.000 & 0.012 & 0.015 & 0.014 & 0.001 \\
\hline \multirow{2}{*}{ Shirt D-3 } & Before WRF & 0.130 & 0.135 & 0.133 & 0.001 & 0.019 & 0.031 & 0.025 & 0.003 \\
\hline & After WRF & 0.123 & 0.126 & 0.125 & 0.000 & 0.009 & 0.012 & 0.010 & 0.001 \\
\hline
\end{tabular}

The effective clothing insulation values were calculated and comparisons were done both graphically as well as statistically. Figure 8 shows the average values of the effective clothing insulation of all shirts obtained before and after WRF. The heat loss value of shirt A decreased after WRF treatment (Figure 5), however, the effective clothing insulation value of shirt A also decreased after WRF treatment. This result can be related to the air gap between the manikin's body and the shirt. Shirt A was a loose fitting $100 \%$ cotton shirt and did not fit very tight to the thermal manikin and there was a higher air gap for shirt A than the other shirts. Therefore, it can be concluded that, the $180 \%$ decrease on effective clothing insulation might be caused by this air gap. Moreover, since the thermal manikin only senses dry heat transfer and all tests were conducted in dry state, the negative effect of poor moisture transportation and release of cotton fabric on thermal insulation is not considered.

Since the testing conditions were $23 \pm 1,5^{\circ} \mathrm{C}$ constant ambient temperature and $60 \pm 5 \%$ relative humidity, which can be consider as a warm environment, lower thermal insulation will provide more heat flux and better thermoregulation. In this scope, it can be considered as more appropriate if the thermal insulation is the same or lower after WRF. The increase in effective clothing insulation of shirt B-1 was not statistically significant ( $\mathrm{p}=0,158)$, where the increase in effective clothing insulation of shirt B was statistically significant $(p=0,000)$.
The decreases in effective clothing insulation of shirt B-2, B-3, D, D-1 D-2 and D-3 were 14\%, 8\%, $18 \%, 42 \%, 84 \%$ and $157 \%$, respectively. Table 4 shows the t-test results of effective clothing insulation values of shirts regarding to water repellent finishing state.

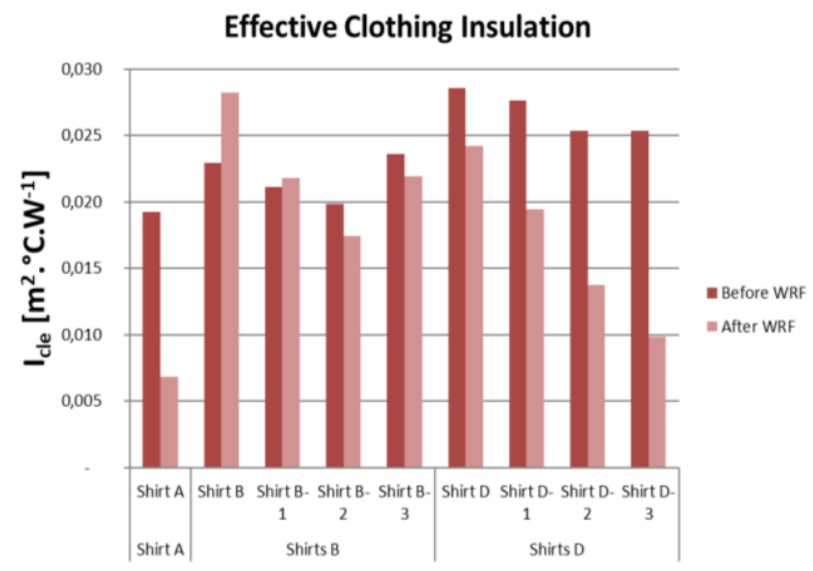

Figure 8. Average values of effective clothing insulation of all shirts

As it can be seen in Table 4, in shirt B-1, there was no significant difference in effective clothing insulation scores between the test results obtained before WRF $(M=0,02$, $\mathrm{SD}=0,002)$ and after WRF $(\mathrm{M}=0,02, \mathrm{SD}=0,001)$; $\mathrm{t}(32,93)=-$ $1,44, \mathrm{p}=0,158$. For shirts A, B, B-2, B-3, D, D-1, D-2 and $\mathrm{D}-3$, it was observed that there was a significant difference in average effective clothing insulation scores between the 
test results obtained before and after WRF. In order to determine the difference within groups and to perform pairwise comparisons, repeated measures ANOVA was used. According to the effective clothing insulation values obtained from the tests before WRF, there was a significant difference between all shirts $(p=0,00)$. With regards to the test results obtained from the tests conducted after WRF, there was a significant difference between all shirts $(\mathrm{p}=0,03)$. Taking into consideration the pairwise tests, there were no significant differences between shirt B and shirt B$2(p=0,717)$, shirt $B$ and shirt $B-3(p=0,313)$ and shirt $D$ and shirt D-1 $(\mathrm{p}=0,099)$.

Regarding to Figure 8 and statistical treatment, shirt B presented higher effective clothing insulation properties, in which the water repellent finishing treatment had an unexpected behaviour. Moreover, the change in effective clothing insulation of shirt B-1 was not statistically significant (Table 4) and this showed that, B-1 seemed to be the only structure that was not influenced from water repellent finishing treatment and it can be concluded the finishing does not affect the thermal comfort properties of shirt B-1.

\section{CONCLUSION}

In the present study, evaluating the effect of water repellent finishing on thermal insulation properties of rowing shirts by using a thermal manikin was aimed. Regarding to the recommendations of the collaborating company, two rowing shirts were chosen, which have three combined knitting structures each. The shirts with these different knitting structures were manufactured as single structures and in addition, one $100 \%$ Cotton shirt was included to the study. The thermal manikin tests were conducted with all shirts and later the shirts were treated with a water-repellent finishing (5\% of a fluorocarbon-based product). After WRF, the thermal manikin tests were repeated in same conditions.

Regarding to the obtained data there was a statistically significant difference in average heat loss scores for all shirts between the tests conducted before and after WRF.

$100 \%$ Cotton shirt had $180 \%$ decrease in effective clothing insulation and this might be caused the lack of the negative effect of poor moisture transportation and release of cotton fabric on thermal insulation. In warmer temperatures, lower thermal insulation provides heat flux and as a conclusion, better thermoregulation. As obtained by the conducted ANOVA tests, shirt B and shirt B-1 had higher effective thermal insulation value after WRF, where the difference was statistically significant $(\mathrm{p}=0,000)$ for shirt $\mathrm{B}$ and the difference was not statistically significant $(p=0,158)$ for shirt B-1. Regarding to literature, the thermal conductivity of cotton fibre is $11,85(\mathrm{~W} /(\mathrm{m} \mathrm{K}))$ while for polyester it is $9,25(\mathrm{~W} /(\mathrm{m} \mathrm{K}))$, for polyamide it is $8,38(\mathrm{~W} /(\mathrm{m} \mathrm{K}))$, and for polypropylene it is $11,18(\mathrm{~W} /(\mathrm{m} \mathrm{K}))$ [25]. Comparing shirts group B with D, shirts group D had greater thermal insulation values although they have polypropylene in their combination instead of polyester. As exists in literature [26], this proves that, the fabric construction such as the channels on the fabric surface or the fibres placed intensely inside surface of the fabric as well as the fabric thickness have significant effect on thermal insulation value in combined materials. The shirts D, D-1 D-2 and D-3, which had $35 \%$ Polypropylene distinctly than the shirts B, B-1, B2 and B-3, had higher difference in effective thermal insulation.

Table 4. The T-Test results for effective clothing insulation values for test series 1 and test series 2

\begin{tabular}{|c|c|c|c|c|c|c|c|}
\hline & & $\mathbf{N}$ & Mean & $\begin{array}{c}\text { Std. } \\
\text { Deviation }\end{array}$ & $\mathbf{t}$ & df & $\mathbf{p}$ \\
\hline \multirow{2}{*}{ Shirt A } & Before WRF & 30.00 & 0.02 & 0.002 & \multirow{2}{*}{40.49} & \multirow{2}{*}{37.96} & \multirow{2}{*}{0.000} \\
\hline & After WRF & 30.00 & 0.01 & 0.001 & & & \\
\hline \multirow{2}{*}{ Shirt B } & Before WRF & 30.00 & 0.02 & 0.003 & \multirow{2}{*}{-11.02} & \multirow{2}{*}{30.36} & \multirow{2}{*}{0.000} \\
\hline & After WRF & 30.00 & 0.03 & 0.000 & & & \\
\hline \multirow{2}{*}{ Shirt B-1 } & Before WRF & 30.00 & 0.02 & 0.002 & \multirow{2}{*}{-1.44} & \multirow{2}{*}{32.93} & \multirow{2}{*}{0.158} \\
\hline & After WRF & 30.00 & 0.02 & 0.001 & & & \\
\hline \multirow{2}{*}{ Shirt B-2 } & Before WRF & 30.00 & 0.02 & 0.002 & \multirow{2}{*}{7.66} & \multirow{2}{*}{31.69} & \multirow{2}{*}{0.000} \\
\hline & After WRF & 30.00 & 0.02 & 0.000 & & & \\
\hline \multirow{2}{*}{ Shirt B-3 } & Before WRF & 30.00 & 0.02 & 0.003 & \multirow{2}{*}{3.45} & \multirow{2}{*}{30.87} & \multirow{2}{*}{0.020} \\
\hline & After WRF & 30.00 & 0.02 & 0.000 & & & \\
\hline \multirow{2}{*}{ Shirt D } & Before WRF & 30.00 & 0.03 & 0.002 & \multirow{2}{*}{11.11} & \multirow{2}{*}{33.47} & \multirow{2}{*}{0.000} \\
\hline & After WRF & 30.00 & 0.02 & 0.001 & & & \\
\hline \multirow{2}{*}{ Shirt D-1 } & Before WRF & 30.00 & 0.028 & 0.002 & \multirow{2}{*}{27.49} & \multirow{2}{*}{38.03} & \multirow{2}{*}{0.000} \\
\hline & After WRF & 30.00 & 0.019 & 0.001 & & & \\
\hline \multirow{2}{*}{ Shirt D-2 } & Before WRF & 30.00 & 0.025 & 0.003 & \multirow{2}{*}{3.391} & \multirow{2}{*}{29.00} & \multirow{2}{*}{0.002} \\
\hline & After WRF & 30.00 & 0.01 & 0.001 & & & \\
\hline \multirow{2}{*}{ Shirt D-3 } & Before WRF & 30.00 & 0.03 & 0.003 & \multirow{2}{*}{26.26} & \multirow{2}{*}{32.13} & \multirow{2}{*}{0.000} \\
\hline & After WRF & 30.00 & 0.01 & 0.001 & & & \\
\hline
\end{tabular}


The combined shirts had different effective clothing insulation values than the single structured shirts and it can be concluded that the garment design has an effect on thermal insulation of shirts. It can be suggested that, before designing process, the single structures should be tested and the results should be considered together with human body thermal and sweating responses during designing fabricbody part combination.

This study proves that, the thermal insulation of rowing shirts change according to the water repellent finishing treatment. Moreover, as it has been discussed in the previous researches [20], not only the water repellent finishing, but also the structure of garment is also important in terms of heat loss and thermal insulation.

Further studies will be conducted by new eco-friendly water repellent finishing products. Moreover, in order to investigate the behaviour of climatic change on thermal insulation of rowing shirts, the thermal manikin tests will be conducted in different air temperature and humidity. In addition, the locked power mode of thermal manikin, which simulates the metabolism during exercise, will be used instead of constant skin temperature mode and the tests will be conducted again in the same climatic conditions.

\section{Acknowledgement}

This work was supported by FEDER funds through the Competitivity Factors Operational Program - COMPETE and by national funds through FCT - Foundation for Science and Technology within the scope of the project POCI-01-0145-FEDER-007136. We would like to thank Elisabeth Martin and Silke Küblbeck for their kind support.

fiber society, 2016 Spring Conference, Textile Innovations Opportunities and Challenges.

13. Secher NS, Volianitis S. 2009. Handbook of sports medicine and science. Rowing, John Wiley \& Sons. Malaysia.

14. Wang F, Song W. 2017. An investigation of thermophysiological responses of human while using four personal cooling strategies during heatwaves. Journal of Thermal Biology, 70, 37-44.

15. Abreu I, Ribeiro P, Abreu MJ. 2017. The issue of thermal comfort of medical clothing in the operating room. DYNA 84(200), 234-239.

16. Shishoo R. 2005. Textiles in sport. Cambridge: Woodhead Publishing Ltd.

17. Horrocks A, Anand S. 2000. Handbook of Technical Textiles. Woodhead Publishing. England.

18. Schindler WD, Hauser PJ. 2004, Chemical finishing of textiles. Woodhead Publishing in Textiles, England.76-83.

19. Rastogi D, Breja K, Goyal N, Jassal M, Agrawal AK. 2013. Comparative analysis of selected fluorocarbon-based oil and waterrepellent finishes on textiles. Research Journal of Textile and Apparel, 17, 20-28.

20. Abreu MJ, Catarino A, Tama D. 2018. Evaluating the effect of fabric type on thermal insulation properties of sports clothing. IOP Conference Series: Materials Science and Engineering, Volume 460.

21. ISO 9920:2007: Ergonomics of the thermal environment - Estimation of thermal insulation and water vapour resistance of a clothing ensemble.

22. Oliveira AVM, Gaspar AR, Quintela DA. 2008. Measurements of clothing insulation with a thermal manikin operating under the thermal comfort regulation mode: comparative analysis of the calculation methods. European Journal of Applied Physiology. Vol. 104, 679-688.

23. Hensel H. 1973. Neural processes in thermoregulation. Physiological Reviews, 53, 948-1017

24. Das A, Alagirusamy R. 2011. Improving comfort in clothing, Chapter 9: Improving tactile comfort in fabrics and clothing, The Textile Institute. Woodhead Publishing Limited, England, 459p.

25. Morton WE, Hearle JWS. 2008. Physical properties of textile fibres, Woodhead Publishing Limited. England.

26. Bhatia D, Malhotra U. 2016. Thermophysiological wear comfort of clothing: An overview. Journal of Textile Science and Engineering, 6, 250. pp. 1-8. 